$p<0.01)$, and low Health Expenditure per capita $(r=0.61, p<0.01)$; the age of RAo did not correlate with $n T$. A significant linear regression equation was found $[F(2,32)=13.61, p<0.01, R 2=0.46]$ in the age of RAo, Health Expenses per capita ( $\beta=0.0007 ; \mathrm{Cl} 95 \% 0.00004$ to 0.001$)$ and PM10 levels $(\beta=-0.044 ; \mathrm{Cl} 95 \%-0.085$ to -0.002 ).

Conclusions: The tropospheric pollutant PM10 and the components of the Health Expenditure per capita such as the provision of health services, family planning activities and nutrition activities are variables worth to further study through hypothesis-testing designs.

References:

[1] GEO-RA Group. Latitude gradient influences the age of onset of rheumatoid arthritis: a worldwide survey. Clin Rheumatol 2016. DOI: 10.1007/s10067016-3481-9.

[2] Essouma M, Noubiap JJ. Is air pollution a risk factor for rheumatoid arthritis? J Inflamm (Lond) 2015; 12:48. DOI: 10.1186/s12950-015-0092-1.

Disclosure of Interest: None declared

DOI: 10.1136/annrheumdis-2017-eular.5509

\section{AB1137 THE ROLE OF SOCIAL DETERMINANTS ON THE PREVALENCE OF RHEUMATIC DISEASES IN LATIN AMERICA. A MULTILEVEL COPCORD STUDY}

J. Moreno-Montoya $^{1}$, C. Pacheco-Tena ${ }^{2}$, Y. Granados ${ }^{3}$, J. Londoño ${ }^{4}$,

S. Guevara-Pacheco ${ }^{5}$, B. Pons-Estel ${ }^{6}$, O. Vega-Hinojosa ${ }^{7}$, M. Garza-Elizondo ${ }^{8}$ M.V. Goycochea-Robles ${ }^{9}$, R. Quintana ${ }^{10}$, F. Julian-Santiago ${ }^{11}$,

J. Alvarez-Nemegyei ${ }^{12}$, A.M. Santos-Granados ${ }^{13}$, R. Burgos-Vargas ${ }^{14}$,

I. Pelaez-Ballestas ${ }^{14}$ on behalf of GEEEMA/GLADERPO. ${ }^{1}$ Epidemiology,

Universidad del Bosque, Bogota, Colombia; ${ }^{2}$ Faculty of Medicine, Universidad

Autonoma de Chihuahua, Chihuahua, Mexico; ${ }^{3}$ Rheumatology Unit, Hospital Dr. Manuel Nuñez Tovar, Maturin, Venezuela, Bolivarian Republic Of; ${ }^{4}$ Faculty of Medicine, Universidad de la Sabana, Bogota, Colombia; ${ }^{5}$ Faculty of Medicine, Universidad de Cuenca, Cuenca, Ecuador; ${ }^{6}$ Rheumalogy Unit, Hospital Provincial, Rosario, Argentina; ${ }^{7}$ Research Unit, Clinica Reumacenter, Juliaca, Peru; ${ }^{8}$ Rheumatology Dpt., Hospital Universitario, Monterrey; ${ }^{9}$ Research Unit, IMSS, Mexico City, Mexico; ${ }^{10}$ Rheumatology Dpt., Hospital Provicial, Rosario, Argentina; ${ }^{11}$ UNAM, Mexico; ${ }^{12}$ Research Unit, HARE, Merida, Mexico:

${ }^{13}$ Universidad de la Sabana, Bogota, Colombia; ${ }^{14}$ Rheumatology Unit, Hospital General de Mexico, Mexico, Mexico

Objectives: To determine the impact of individual and regional variables on the geographic distribution of RD across six Latin-American countries

Methods: This is a secondary multilevel analysis of cross-sectional data of COPCORD studies that investigated the prevalence of RD in Argentina, Colombia, Ecuador, México, Peru, and Venezuela. Individual factors were sex, age, comorbidities, job status, and Health Assessment Questionnaire (HAQ) score. Contextual level variables were country and subject's identification as indigenous. RD predictors, including individual and regional variables, particularly indigenous status were identified with logistic regression models. The effect of contextual variables was estimated with median odds ratio's $(\mathrm{OR})$ estimation.

Results: Most individuals included in this analysis came from urban areas (82.40\%); their mean age was 43.12 years $(95 \% \mathrm{Cl} 43.01-43.35)$; and $56.0 \%$ were women. Nearly all of them reported $>1$ comorbidity (94.70\%) and $72.19 \%$ were economically active. The prevalence of any RD varied from $1.55 \%$ in Peru to $26.09 \%$ in Argentina. The mean prevalence of Rheumatoid Arthritis (RA) was 1.58 (range 0.64 to 2.47) (table 1). Aside comorbidities, individual level variables associated to any RD were sex (OR: $1.35 ; 95 \% \mathrm{Cl} 1.28-1.43$ ), age (OR: $1.02 ; 95 \% \mathrm{Cl} 1.01-1.03$ ), and HAQ score (OR: 3.71; 95\% Cl 3.22-4.28). Crude comparisons showed significant variations among countries $(\mathrm{p}<0.01)$ and indigenous groups (OR: $1.69 ; 95 \% \mathrm{Cl} 1.58-1.81)$. These findings were confirmed by adjusted analysis (Median OR 1.26; $95 \% \mathrm{Cl} 1.14-1.38$ ) (table 2).

Table 1. General prevalences and sample sizes across countries

\begin{tabular}{lcccccc}
\hline Country & $\mathrm{n}$ & $\%$ & \multicolumn{4}{c}{ Prevalence \% } \\
\cline { 4 - 7 } & & & Any RD & RA & OA & Fibromyalgia \\
\hline Argentina & 1656 & 3.94 & 26.09 & 2,42 & 3.86 & 0.06 \\
Colombia & 6734 & 16.01 & 6.53 & 0,64 & 5.18 & 0.25 \\
Ecuador & 4877 & 11.60 & 13.2 & 0,88 & 10.58 & 2.05 \\
Mexico & 22175 & 45.69 & 18.34 & 2,47 & 12.01 & 0.82 \\
Peru & 1095 & 2.60 & 1.55 & 0,65 & 0.55 & 0.09 \\
Venezuela & 5512 & 9.45 & 14.94 & 0,9 & 16.47 & 0.38 \\
Total/General & 42049 & 100.00 & 16.00 & 1,58 & 10.42 & 0.77 \\
\hline
\end{tabular}

Table 2. Individual and contextual factors associated to any RD

\begin{tabular}{lcccr}
\hline Any rheumatic diseases & OR & $p$ & \multicolumn{2}{c}{$95 \%$ IC } \\
\hline Any comorbidities & 1,676 & $<0,001$ & 1,542 & 1,821 \\
Age (yrs) & 1,019 & $<0,001$ & 1,017 & 1,022 \\
HAQ & 2,456 & $<0,001$ & 2,240 & 2,693 \\
Schooling level & 0,970 & $<0,001$ & 0,962 & 0,978 \\
\hline \multicolumn{2}{l}{ MOR $^{\star}$} & $\mathrm{p}$ & \multicolumn{2}{c}{$95 \%$ IC } \\
\hline Indigenous vs. Non-indigenous & 1,266 & 0,015 & 1,146 & 1,386 \\
\hline
\end{tabular}

Conclusions: There common factors associated to the prevalence of RD in the region, however, the estimation of its impact varies in significant way across countries and related to the fact of belong to an indigenous group indicating an increase in the estimated ORs.

Acknowledgements: National Council for Science and Technology (CONACYT);Colegio Mexicano de Reumatologia (Mexico). EsSalud (Perú). Universidad de Cuenca (Ecuador).ASOREUMA (Colombia). Federico Wilhelm Agricola Foundation (Argentina). PDVSA East, SUELOPETROL and Bristol-Myers Laboratory (Venezuela)

Disclosure of Interest: None declared

DOI: 10.1136/annrheumdis-2017-eular.3305

\section{AB1138 ENGAGEMENT IN A UK SMARTPHONE STUDY EXAMINING THE ASSOCATION BETWEEN WEATHER AND PAIN: PRELIMINARY RESULTS FROM CLOUDY WITH A CHANCE OF PAIN}

$\underline{\text { K.L. Druce }}^{1}{ }^{\text {, J. McBeth }}{ }^{1,2}$, S.N. van der Veer ${ }^{1}$, D.A. Selby ${ }^{3}$, B. Vidgen ${ }^{4}$

K. Georgatzis ${ }^{5}$, A.M. Chowdry ${ }^{1}$, R. Lakshminarayana ${ }^{6}$, D.M. Schultz ${ }^{7}$,

C. Sanders ${ }^{8}$, J.C. Sergeant ${ }^{1,2}$, W.G. Dixon ${ }^{1,2}$. ${ }^{1}$ Arthritis Research UK Centre for Epidemiology, University of Manchester; ${ }^{2}$ NIHR Manchester Musculoskeletal Biomedical Research Unit, Central Manchester University Hospitals NHS Foundation Trust, Manchester; ${ }^{3}$ Department of Statistics, University of Warwick, Coventry: ${ }^{4}$ Oxford Internet Institute, University of Oxford, Oxford: ${ }^{5}$ School of Informatics, University of Edinburgh, Edinburgh; ${ }^{6}$ uMotif, London; ${ }^{7}$ Centre for Atmospheric Science, School of Earth and Environmental Sciences; ${ }^{8}$ Medical Sociology, Division of Population Health, Health Services Research and Primary Care, University of Manchester, Manchester, United Kingdom

Background: Smartphones can facilitate collection of temporally-rich selfreported data, and have proven to enable large recruitment. However, their viability to support epidemiological research is uncertain due to concerns about selection bias and unsustained engagement.

Objectives: To examine the characteristics and engagement of participants in the first six months of Cloudy with a Chance of Pain, a UK smartphone-based study investigating the link between the weather and chronic pain.

Methods: Between 20th of January and 29th of February 2016, we recruited UK residents 17 years or older with chronic pain ( $\geq 3$ months) who owned a smartphone. Participants received prompts from an app developed by uMotif, which they used to daily report the severity of ten pain-related symptoms. Of those who enrolled, those eligible for analysis provided sufficient baseline data to confirm they were $\geq 17$ years old, and at least one symptom. The characteristics of those who were eligible were examined. Engagement per day was defined based on whether participants had completed any of the ten symptoms. Participants were then clustered by their engagement over time using a first-order hidden Markov models. Participant characteristics were then compared between the clusters.

Results: Of 7972 people who registered to participate, 6370 were eligible. $81 \%$ of participants were female, with a mean age of 49 years (SD 12.9). The most common diagnosis was arthritis (40\% type unspecified, $19 \%$ rheumatoid arthritis), followed by fibromyalgia/chronic widespread pain (24\%) and "other pain diagnosis" (23\%). We identified four clusters of engagement: high (14\%), moderate $(22 \%)$, low (39\%) and tourists (25\%). Median days of data entry ranged from $1(1-1)$ to 175 (IQR: 152-177) for the tourist and high engagement clusters respectively. Those in the high and moderate clusters $(n=2249,35 \%)$ engaged on at least $50 \%$ of days in the study (high: $79 \%$; moderate: $50 \%$ ). Highly engaged participants were older (median 56 (47-63)) when compared to those who were low engagers (47 (39-57)) or tourists (49 (40-58)). A lower proportion of tourists were women (76\% (95\% Cl: 74-78), than in any other cluster (high: $82 \%(80-85)$, moderate: $84 \%(82-86)$, low: $81 \%(79-82))$.

Conclusions: Cloudy with a Chance of Pain recruited a large sample of people with chronic pain, of whom over one in three participants engaged in smartphone-based symptom reporting for at least $50 \%$ of days in the first six months. Smartphone studies enable quick mass participation with sustained daily data entry, providing unprecedented volumes of daily data. While there may be selection bias towards older females in our study, younger men are also less likely to participate in studies using traditional data collection methods. Our study suggests that smartphones could provide a viable alternative to traditional data collection methods.

Disclosure of Interest: None declared

DOI: 10.1136/annrheumdis-2017-eular.2692

\section{AB1139 AUTOANTIBODY AGAINST COMPLEMENT COMPONENT 1Q SUBCOMPONENT IS ASSOCIATED WITH THE PATHOGENESIS OF RECURRENT PREGNANCY LOSS}

K. Ohmura $^{1}$, K. Oku ${ }^{1}$, T. Kitaori ${ }^{2}$, M. Kono ${ }^{1}$, S. Tanimura ${ }^{1}$, E. Sugawara ${ }^{1}$, R. Hisada ${ }^{1}$, H. Nakamura ${ }^{1}$, S. Shimamura ${ }^{1}$, Y. Fujieda ${ }^{1}$, M. Kato ${ }^{1}$, T. Bohgaki ${ }^{1}$, O. Amengual ${ }^{1}$, S. Yasuda ${ }^{1}$, M. Sugiura-Ogasawara ${ }^{2}$, T. Atsumi ${ }^{1}$. ${ }^{1}$ Division of Rheumatology, Endocrinology and Nephrology, Hokkaido University Graduate School of Medicine, Sapporo; ${ }^{2}$ Department of Obstetrics and Gynecology, Nagoya City University Graduate School of Medical Sciences, Nagoya, Japan

Background: In recurrent pregnancy loss (RPL), the pathogenesis of the majority of cases remains to be explained. Antiphospholipid, syndrome (APS) is one 